\title{
Differences in on-ground and aloft conditions explain seasonally different migration paths in Demoiselle crane
}

\author{
Batbayar Galtbalt ${ }^{1,2^{*}}$ D , Nyambayar Batbayar², Tuvshintugs Sukhbaatar², Bernd Vorneweg ${ }^{3}$, Georg Heine ${ }^{3}$, \\ Uschi Müller ${ }^{3}$, Martin Wikelski ${ }^{3}$ and Marcel Klaassen ${ }^{1}$
}

\begin{abstract}
Background: Although some migratory birds may take different routes during their outbound and inbound migration, the factors causing these differential migrations to and from the breeding grounds, have rarely been investigated. In Northeast Asia, Demoiselle crane (Anthropoides virgo) performs one of the most extreme "loop" migrations known to date. During outbound migration, they cross the Himalayas to non-breeding sites in northwest India. Contrastingly, during inbound migration to the breeding grounds, they fly around the western end of the Himalayas. We hypothesise that differences in prevailing environmental conditions aloft and/or on-ground during both seasonal migrations are at the core of this phenomenon.
\end{abstract}

Methods: Based on the tracking data of 16 individuals of tagged Demoiselle crane, we compared conditions during actual migration with those of simulated "reverse" migration (i.e. by adding 180 degrees to the flight direction and adding and subtracting half a year to the timestamps of outbound and inbound migration, respectively).

Results: The comparison of actual and simulated "reverse" migration indicated that cranes would have encountered poorer aloft (wind support and thermal uplift) and on-ground conditions (temperature) if they had migrated in a reverse outbound migration and poorer on-ground conditions (Normalised Difference Vegetation Indexes [NDVI]) if they had migrated in a reverse inbound direction.

Conclusions: Our analyses suggest that both on-ground and aloft conditions play a key role in explaining Demoiselle cranes' loop migration, during the periods that they chose to use these alternative routes. Knowledge on the determinants of (differential) migration routes allow predicting migration decisions and may be critical in mitigating global change effects on animal migrations.

Keywords: Loop migration, Environmental conditions, Wind support, Thermals, Temperature, NDVI, Anthropoides virgo

\section{Background}

It is well established that some migratory animals may follow widely different routes during outbound and inbound migration (i.e. migration from and to their

\footnotetext{
*Correspondence: batbr19@gmail.com

${ }^{1}$ Centre for Integrative Ecology, School of Life and Environmental Science, Deakin University, Victoria, Australia

Full list of author information is available at the end of the article
}

breeding grounds, respectively), also known as "loop" migration [1]. The use of different routes may be agedependent and occur only once during a life cycle, such as in Sharp-tailed sandpipers (Calidris acuminata) that breed in Arctic Siberia and spend the non-breeding season in Australasia. Whereas the adults follow the East Asian coast during their biannual migrations, juveniles often fly across the Bearing Strait to Alaska and then on 
to Australasia [2]. It may also be an annually recurring phenomenon for all ages, such as in American golden plover (Pluvialis dominica) [3] and Red-backed shrike (Lanius collurio) [4]. The hypothesised reasons for these differential migration routes are thought to be related to their consequences for the migrants' time and energy budgets as well as their safety $[1,5]$, i.e. the three key factors that are thought to have shaped animal migratory behaviour [6].

Differential seasonal migration routes have been predominantly documented in avian species. Few of these studies profoundly researched the underlying causes for this phenomenon and generally assumed that it is an adaptation to differential seasonal variations in prevailing environmental condition along the two alternative routes [4, 7-14]. Klaassen et al. [9] tracked 14 Marsh harriers (Circus aeruginosus) to investigate the effect of the availability of suitable habitat and prevailing wind conditions on their migration path. They found that only wind was able to explain the Marsh harriers' somewhat more easterly migration route between North-western Europe and Western Africa during outbound compared to inbound migration. Using on-the-ground observations, Sorte et al. [8] found that during inbound spring migration, 26 terrestrial bird species in the Western Flyway of North America followed a lower-elevation, less-direct route because of locally higher ecological productivity during that time of year. On the other hand, in the Eastern Flyway of North America, many birds undertake their outbound migration to the east of their inbound migration to make use of prevailing wind conditions over the Atlantic Ocean $[1,15,16]$. Also for birds in the Afro-Palearctic flyway, many examples of seasonally differential migratory routes have been documented, including Eleanor's falcon (Falco eleanorae) [10], Red-backed shrike (Lanius collurio) [4], Common cuckoo (Cuculus canorus) [17], Barn swallow (Hirundo rustica) [7, 18], Northern wheatear (Oenanthe oenanthe) [11] and Nightjar (Caprimulgus europaeus) [19]. Consequently, researchers have argued that loop migration might well be the predominant strategy in this flyway $[4,19]$. In addition to these examples of terrestrial bird species, several marine birds including Manx shearwater (Puffinus puffinus) in the Atlantic [20], and Sooty shearwater (Puffinus griseus) in the Pacific Oceans [13] have been found to undertake loop migrations, which have been suggested to be driven by prevailing large-scale wind patterns [21]. In all cases, it has been assumed that variations in environmental conditions along the alternative migratory tracks, both aloft (during migratory flight) and on the ground (during migratory staging), are the core determinants for the choice of the specific migratory route.
Compared to all the above examples of loop migration, Demoiselle cranes (Anthropoides virgo) from the eastern parts of their distribution range in East Asia, have an exceptionally pronounced loop migration using dramatically different migratory routes during outbound and inbound migration. They migrate across the Himalayas during their outbound migration, but rather than flying back along the same route from their wintering grounds in Gujarat, India, they instead make a loop migration around the western end of the Himalayas [22, 23] and next fly in easterly direction, 1700 to $2650 \mathrm{~km}$ to the north of their outbound migratory track (Fig. 1). The reason for these vastly different seasonal migration routes is unknown and has not been investigated previously.

To add to the limited knowledge base on the drivers for loop migrations we aimed at identifying these for the extreme loop migration of Demoiselle cranes in East Asia. Hypothesising that also in this case variations in environmental conditions during the two migratory seasons may drive the preference for the two routes, we investigated temporal variations in environmental conditions and how these might affect migratory behaviour. To this end, using GPS-GSM tracking along with meteorological and Normalised Differential Vegetation Index (NDVI) data, we analysed the suitability of the environmental conditions on the ground for foraging and aloft for migratory flight along both outbound and inbound routes. We conducted these analyses at the time of their respective migrations along both trajectories, but also for a simulated, reverse-loop migration, reversing the birds' flight direction and changing the timestamp by approximately half a year. Since wind conditions may importantly impact the energy and time costs of avian migration $[24,25]$, and also thermal uplift may play a role, notably in species such as cranes that may also engage in soaring flights during migration [26, 27], we considered both wind support and thermal uplift at flight height as potentially critical conditions aloft for migration. For on-ground, migratory-staging conditions we considered surface air temperature and plant biomass (i.e. NDVI) as proxy measures of foraging conditions. During migration Demoiselle cranes are known to forage mainly on crops and insects $[28,29]$, of which the availability is highly correlated with surface temperature [30,31] and NDVI [32].

However, in so comparing conditions aloft and onground during actual and reverse migration, we did not account for the possibility that migrants may make use of short-term temporal variations in environmental conditions and notably wind conditions [33, 34]. Many migrants have been shown to pass through staging areas in peaks rather than at a continuous rate, occasionally delaying migration to wait for more favourable migratory conditions (e.g. Cygnus bewickii; $[35,36])$. As 


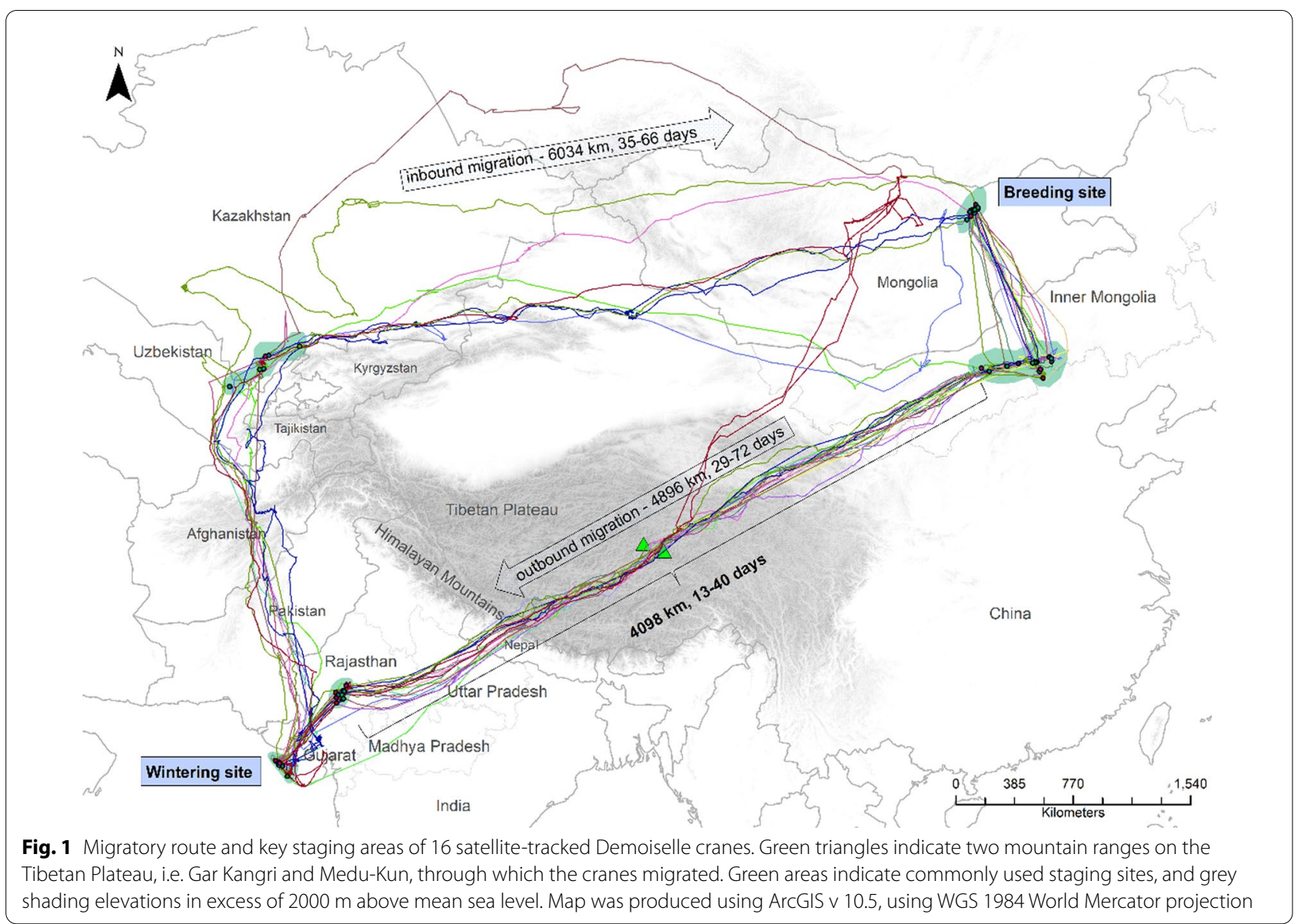

a consequence, directly comparing the favourability of actual migratory conditions during one season with time-shifted (i.e. by half a year) conditions during the alternative season (i.e. reverse-simulated migration) would ignore the possibility of such fine-tuning on the actual migratory conditions. To investigate the potential bias in our comparison of actual with reverse-simulated migrations due to the possible existence of migratory fine-tuning, we also studied the effects of relatively small time-shifts (i.e. days to weeks) on migratory conditions aloft. We conducted this for aloft and not for on-ground conditions since conditions aloft are more variable from day to day than on-ground conditions.

\section{Methods}

\section{Tracking and environmental data acquisition}

We caught nine adult and eighteen juvenile Demoiselle cranes at their breeding ground in Northeast Mongolia (N48.3 ; E110.3 ${ }^{\circ}$ in both 2016 and 2019. The adults were caught using leg snare traps between 15 and 25 June whereas the juveniles were caught by hand shortly before fledging between 5 and 7 August. We deployed $15 \mathrm{~g}$, solar-powered GPS/GSM transmitters (produced by Max-Planck Institute of Animal Behavior-University of Konstanz, Germany) on the right tibiotarsus of each individual using the method described in Ellis et al. [37]. The transmitters were programmed to record positions at 20 min intervals and had a geographic positioning accuracy of $\pm 10 \mathrm{~m}$ while altitude was measured with an accuracy of $\pm 25 \mathrm{~m}$.

Data from 16 out of the 27 transmitters were included in the analysis as data from eleven transmitters logged very few points or discontinued functioning before migration completion. Excluding the breeding $\left(>48^{\circ} \mathrm{N} ;>110^{\circ} \mathrm{E}\right)$ and wintering grounds $\left(<27^{\circ} \mathrm{N} ;<75^{\circ} \mathrm{E}\right)$, the transmitters produced 61,136 migration data points, which were classified as either "in-flight" or "stationary" for the analysis of migration in relation to conditions aloft and on-ground, respectively. We classified the fix as in-flight if ground speed (instantaneous measurements provided by the transmitter) was greater than $3 \mathrm{~m} / \mathrm{s}$ and step length (distance between consecutive fixes) was above $5 \mathrm{~km}$, and stationary if ground speed was less than $1 \mathrm{~m} / \mathrm{s}$. We omitted 5143 data points that did not meet any of these criteria. Stopover sites were defined as sites where birds spend more than two days within a radius of 
ten kilometres. Any in-flight fixes during a stopover were removed from the data set. Fixes outside the geographic breeding and wintering grounds as defined above and within the periods September to December and March to May were assigned as representing outbound (autumn; 2315 in-flight and 19,349 stationary fixes comprised of 21 migration events of 16 individuals) and inbound (spring; 2818 in-flight and 18,813 stationary fixes comprised of nine migration events of seven individuals) migration, respectively.

We annotated each in-flight fix with conditions aloft (i.e. wind support and thermal uplift) and each stationary fix with on-ground conditions (i.e. ambient temperature at $2 \mathrm{~m}$ above ground level and Normalised-Difference Vegetation Index, NDVI). The spatially and temporally specific meteorological variables used for calculating wind support and thermal uplift were obtained from the European Centre for Medium-Range Weather Forecast's (ECMWF) ERA-5 hourly dataset for 18 pressure levels between 400 to 1000 hectopascal, via the Copernicus Climate Data Store [38]. Ambient temperature and NDVI were obtained via the Env-DATA system, which also uses data from ERA-5 and the National Aeronautics and Space Administration (NASA) as its primary data source for former and latter respectively [39]. The ERA-5 dataset has a spatial resolution of 0.25 degrees and a vertical resolution of 250-500 m, while for NDVI the spatial resolution was $250 \mathrm{~m}$ with a temporal resolution of 16 days. To obtain the most probable NDVI estimate at each fix we used bilinear spatio-temporal interpolation available within the Env-DATA system. The extracted wind data at the bird's flight height, west to east (zonal, $\mathrm{U}_{\mathrm{z}}, \mathrm{m} / \mathrm{s}$ ) and south to north (meridional, $\mathrm{V}_{\mathrm{m}}, \mathrm{m} / \mathrm{s}$ ) wind components, together with flight direction (i.e. the direction in which the bird flies, $\theta_{f}$, which was estimated based on consecutive fixes using the 'angle' function within R-package move [40]) were used to calculate wind support (WS, $\mathrm{m} / \mathrm{s}$ ) following Safi et al. [41], using:

$$
W S=\sqrt{V_{m}^{2}+U_{z}^{2}} \times \cos \left(\operatorname{atan} 2\left(V_{m}, U_{z}\right)-\frac{2 \pi \theta_{f}}{360}\right)
$$

We estimated thermal uplift following Bohrer et al. [42], using:

$$
\omega^{*}=[g z H / T]^{1 / 3}
$$

where $g$-gravitational acceleration, $z$ is boundary layer height, $H$ is the surface sensible heat flux and $T$ is potential temperature.

\section{Simulation of reverse and time-shifted migration}

Using the recorded migration tracks and both in-flight and on-ground fixes, we simulated reverse migration using a seasonal time-shift to evaluate what atmospheric and on-ground conditions cranes would likely encounter if they would fly north using the outbound migratory path and south using the inbound migratory path. The process (graphically outlined in Fig. S1) started with reversing the time stamps of each individual's outbound and inbound migration track. Next, we added 180 degrees to the birds' flight directions (since flight directions are used for calculation of wind support). Finally, we added 195 days to the timestamps of outbound and subtracted 195 days from the timestamps of inbound migrations. These timestamp modifications were based on the median departure and arrival dates of September 6th and October 22nd for outbound and March 25th and May 08th for inbound migration, respectively. The simulated migration data were subsequently annotated with environmental condition data as described above.

To investigate the potential bias in our comparison of actual with reverse-simulated migrations due to the possible existence of migratory fine-tuning, we studied the effects of fixed time-shifts on migratory conditions aloft. Using all in-flight fixes of the original tracks, we systematically changed the timestamp by adding or subtracting either one to seven days, two weeks, or a one-month time period, resulting in a total of 18 different time-shift scenarios [43]. These time-shifted data sets were subsequently annotated with wind and thermal uplift following the same procedures as outlined above and compared with the annotated data of the original tracks.

\section{Analysis}

All calculations and statistical analyses were conducted in $R$ v. 4.1.1 [44]. To evaluate whether migratory conditions aloft and/or on-ground can explain the cranes outspoken loop-migration, we tested for differences in environmental conditions between actual and simulated reverse migration using linear mixed effect models. A total of eight tests were conducted in which each of the four environmental variables during both outbound and inbound migration were used as a response variable, and data type (either actual or simulated) was entered as a fixed effect and individual crane as a random effect explanatory variable. In the analyses we allowed for both a random intercept as well as a random slope to account for individual variation. For the four tests involving wind support and thermal uplift we used in-flight fixes only, while for the four tests involving the on-ground environmental variables temperature and NDVI we used stationary fixes only.

We tested if cranes are potentially fine-tuning their timing of migration to conditions aloft (wind support and thermal uplift) for outbound and inbound migration separately, yielding a total of four linear mixed effect 
models. In each of these models, using an in-flight data set combining the conditions aloft during actual migration as well as all 18 time-shifted scenario's we used timeshift (ranging from 0 days to 1 month) as a (categorical) fixed effect and fix-ID nested within individual crane as random effect explanatory variables. Subsequent to each linear mixed effect model, to evaluate whether or not conditions were on average more favourable during actual than time-shifted migrations, we ran multiple comparison tests between the zero time-shift (actual) and all other time-shifts using the glht function and Dunnett contrasts [45] in package multcomp in R.

\section{Results}

Environmental conditions aloft and on the ground varied greatly along both outbound and inbound migratory routes (Additional file 1: Table S1). As for the conditions aloft, wind support during inbound was significantly higher than outbound migration, while thermal uplift was similar (wind support: $t$ test $=16.7, d f=4663, p<0.001$; thermal uplift: $t$ test $=-0.09, d f=4,083, p>0.05)$. On the other hand, on-ground conditions differed significantly between outbound and inbound migrations, with temperature being higher during outbound $(t$ test $=-14.07$, $d f=37,996, p<0.001)$ and NDVI being higher during inbound migration $(t$ test $=11.5, d f=36,468, p<0.001$ ). We provided detailed summaries of migration phenology and en-route environmental conditions in the Additional file 1.

\section{Actual and simulated "reverse" migratory routes in relation to environmental condition}

While comparisons of conditions aloft during actual and simulated migrations gave variable results, cranes would generally have encountered either poorer on-ground and/or aloft condition if they had migrated a simulated reverse route (Figs. 2, 3, Table 1). Wind support was better during actual outbound than simulated reverse migration. During inbound migration, wind support did not differ between actual and simulated reverse migration. Also thermal uplift during actual outbound migration was higher than during simulated reverse migration, it

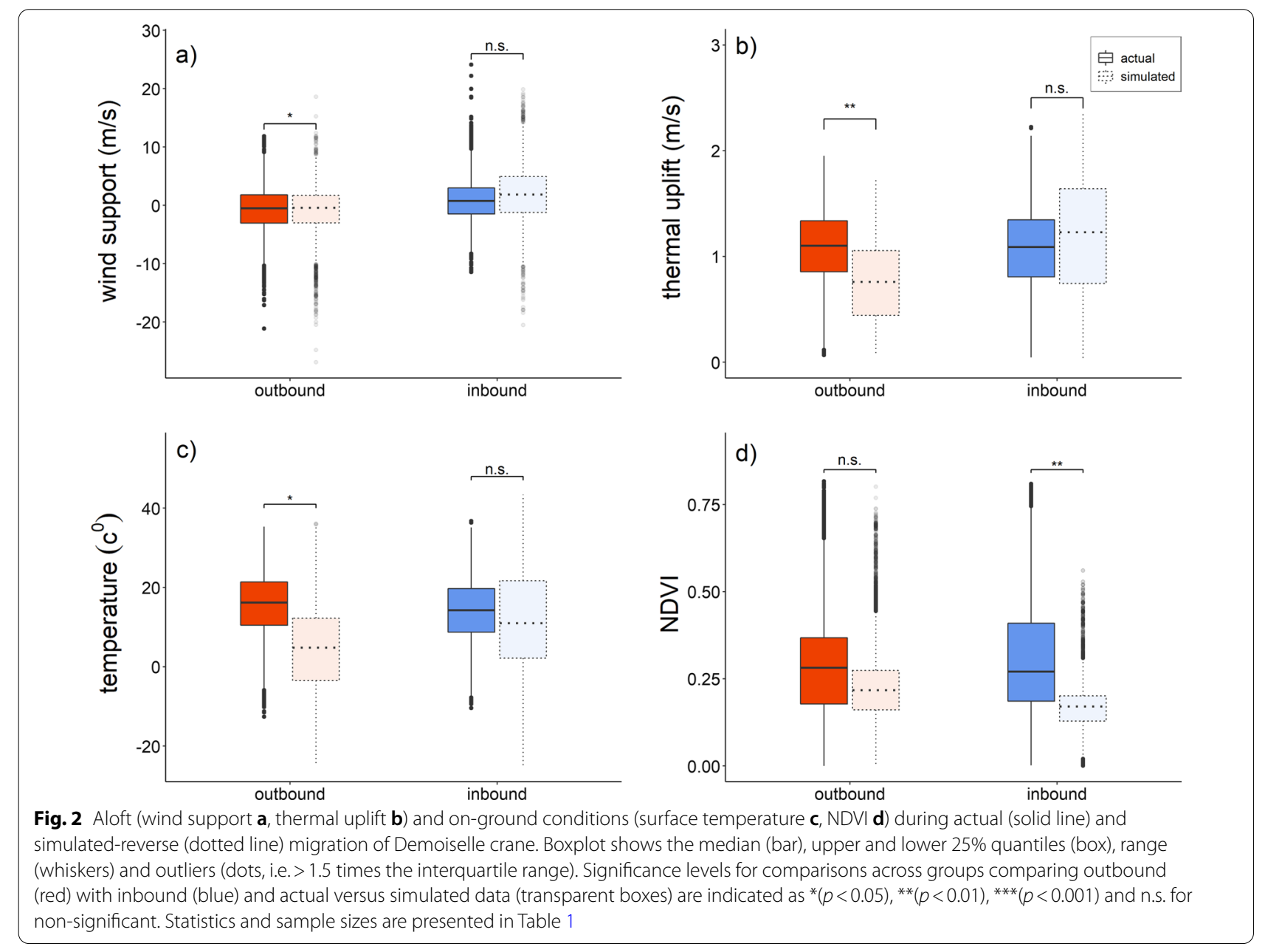


was similar during inbound migration. The surface temperature of actual outbound migration was three-fold higher than that of simulated reverse migration, while it did not differ between actual inbound and simulated reverse migration. For NDVI the reverse pattern was found, where NDVI was similar during actual and simulated reverse outbound migration, while, it was $86 \%$ higher for actual inbound compared to simulated reverse migration.

\section{Comparison of conditions aloft during actual and simulated "time-shifted" migration}

Cranes' actual migratory conditions aloft were generally better than when time-shifted, with the exception of some cases of outbound thermal uplift (Fig. 4). During outbound migration, the cranes' actual migration days had consistently better wind support than at other time-shifted moments (Fig. 4; Additional file 1: Table S2). During inbound migration, cranes also selected actual migration days with higher wind support compared to one-day-earlier and later, and also five to seven days and a month later time-shifts (i.e., $-1 \mathrm{~d},+1 \mathrm{~d},+5 \mathrm{~d}$ to $+7 \mathrm{~d}$, and $+1 \mathrm{~m}$ ), even though the majority of time-shifted migrations had positive (i.e., more) wind support (Fig. 4; Additional file 1: Table S3). Similarly, the cranes' actual migration days had better thermal uplift than most of the time-shifts, notably when compared with earlier timeshifts. During outbound migration, the cranes' actual migration days had higher thermal uplift than during the majority of the time-shifts. However, conditions would have been similar if they had migrated one to two weeks before or one to three days later (Fig. 4; Additional file 1: Table S4). During inbound migration, actual migration days also had higher thermal uplift than all earlier timeshifts as well as the one-day-later time-shift. It should be noted though that thermal uplift is expected to increase day by day in spring, following the gradual increase in ambient temperature. Hence, cranes would have had even higher thermal uplift if they had migrated four days later (Fig. 4; Additional file 1: Table S5).

\section{Discussion}

Demoiselle cranes apparently undertake their loop migration to exploit both favourable stopover, on-ground, as well as aloft conditions. At refuelling sites NDVI is an important correlate of food supply for migrants $[1,46-$ 49]. By migrating via a more northerly inbound route, rather than using the trans-Himalayan trajectory used during outbound migration, the cranes experienced $86 \%$ more vegetation cover than if they had engaged in a straight return migration across the Himalayas (i.e. a simulated reverse migration). During outbound migration, by crossing the Himalayas rather than avoiding them using a northern loop, the birds experienced better wind support, thermal uplift and higher surface temperatures (see Fig. 2). In the final stages of the preparation of this manuscript we became aware of the work of Mi et al. [50] who similarly to us investigated the environmental factors underlying the distinguished loop migration in Demoiselle cranes. While using different data set and analyses their conclusions importantly ovelap in that both aloft and on-ground conditions appear to be key on explaining the differential migration routes for inbound and outbound migration. It has been suggested that TransHimalayan spring migration might be a harsh undertaking for waterfowl [51]. Notably in spring, on-ground conditions on the Tibetan Plateau often involving subzero temperatures, potentially impacting food availability, resulting in a true migration barrier for birds such as cranes that require en route replenishment of fuel stores [28, 52-54]. Despite this, many raptors and waterfowl nevertheless do cross the Himalayas during spring migration, following a similar route as their trans-Himalayan outbound migration [55-57]. These differences between cranes on the one hand and raptors and waterfowl on the other, may be explained by flight mode and feeding ecology. Migration is most costly for migrants using powered, flapping flight $[1,58]$ such as waterfowl. Detours around barriers may thus be more costly for such birds than for soaring migrants or those using a mixture of soaring and powered flight, such as cranes. Next, raptors which mainly prey on mammals and birds may be less impacted by low vegetation cover. Also herbivores that are not only relying on above ground vegetation but also forage on tubers and stolons, such as many herbivorous waterfowl, may be less sensitive to low above ground vegetation cover. In contrast, Demoiselle cranes mainly feed on items that are available only when the productive season has already somewhat progressed (cultivated crops and their remains, other above ground vegetation) $[28,59]$. Thus, the loop migration of Demoiselle cranes is probably best explained in terms of their specific dietary needs and relatively low flight costs while being able to soar.

Additional support for the importance of aloft conditions shaping migration strategies comes from the comparisons of simulated time-shifted migration with actual

(See figure on next page.)

Fig. 3 Actual migration (left) and simulated "reverse" migration path (right) of Demoiselle crane in relation to wind support (a, b), thermal uplift $(\mathbf{c}, \mathbf{d})$, temperature $(\mathbf{e}, \mathbf{f})$ and vegetation (NDVl; $\mathbf{g}, \mathbf{h}$ ) condition. The arrows indicate direction of (simulated) migration. Major staging sites where all birds stay during migration are highlighted by a numbered oval circle on the maps depicting on-ground conditions (e, $\mathbf{f}, \mathbf{g}$, $\mathbf{h}$ ): 1 - staging site in Inner Mongolia, 2-staging site near Aydar lake, south Kazakhstan 


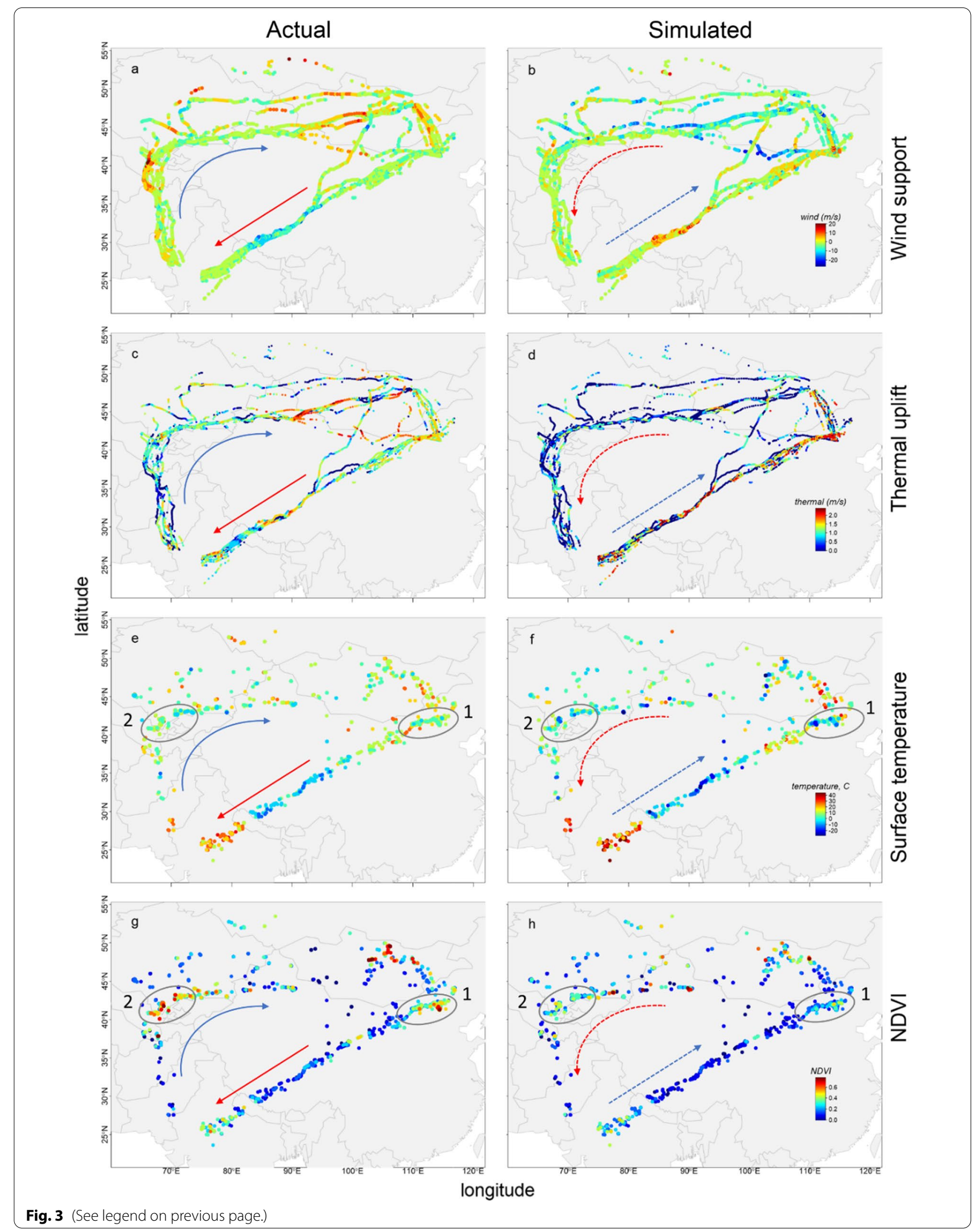


Table 1 Results of linear mixed effect models testing how conditions aloft (wind support and thermal uplift) and on-ground (temperature and NDVI) compare between reverse simulated migration and actual migratory conditions during both outbound and inbound migration

\begin{tabular}{|c|c|c|c|c|c|c|}
\hline \multirow[t]{2}{*}{ Dependent variable } & \multirow[t]{2}{*}{ Comparison (sample size, $\mathrm{n}$ ) } & \multirow{2}{*}{$\begin{array}{l}\text { Route } \\
\text { comparison }\end{array}$} & \multicolumn{4}{|c|}{ Simulated-Actual } \\
\hline & & & Estimate & Std. Error & $t$ & $p$ value \\
\hline \multirow[t]{2}{*}{ Wind support } & sim. outb $(n=2779)-$ act. outb $(n=2315)$ & N-S & -1.94 & 0.69 & -2.82 & $<0.05$ \\
\hline & sim. inb $(n=2279)-$ act. inb $(n=2818)$ & $\mathrm{S}-\mathrm{N}$ & 0.04 & 0.52 & 0.08 & 0.94 \\
\hline \multirow[t]{2}{*}{ Thermal uplift } & sim. outb $(n=1174)-$ act. outb $(n=2054)$ & N-S & -0.38 & 0.07 & -5.26 & $<0.01$ \\
\hline & sim. inb $(n=1238)-$ act. inb $(n=2171)$ & $\mathrm{S}-\mathrm{N}$ & 0.17 & 0.08 & 2.05 & 0.07 \\
\hline \multirow[t]{2}{*}{ Temperature } & sim. outb $(n=18,831)-$ act. outb $(n=19,349)$ & N-S & -8.26 & 2.85 & -2.90 & $<0.05$ \\
\hline & sim. inb $(n=19,349)-$ act. inb $(n=18,313)$ & $\mathrm{S}-\mathrm{N}$ & -0.02 & 2.73 & -0.01 & 0.99 \\
\hline \multirow[t]{2}{*}{ NDVI } & sim. outb $(n=18,416)-$ act. outb $(n=18,669)$ & N-S & -0.03 & 0.02 & -1.73 & 0.10 \\
\hline & sim. inb $(n=18,201)-$ act. inb $(n=19,207)$ & $\mathrm{S}-\mathrm{N}$ & -0.12 & 0.03 & -3.68 & $<0.01$ \\
\hline
\end{tabular}

Positive estimates indicate that the values are higher during reverse simulated migration, while negative estimates indicate they are higher during actual migration. The capital letter $\mathrm{N}$ denotes the northern route, while $\mathrm{S}$ denotes the southern route, crossing the Himalayas

migration data showing that they tended to undertake migratory flights on days with more favourable tailwind and thermal uplift (see Fig. 4). In addition, we found that cranes undertook the majority of migratory flights during midday when intensity of thermal uplift is at its highest (see Additional file 1: Fig. S2). That partially soaring migrants actively select days of favourable thermal conditions has not been investigated previously, although Common cranes (Grus grus) occasionally undertake soaring migration flights $[26,27]$. To summarise, while both on-ground and aloft conditions are critical in explaining the loop migration of Demoiselle cranes, condition aloft may impact flight costs and importantly determine the actual days on which migrations take place.

The energetic consequences of variations in conditions aloft for migrants have been shown to determine variations in migratory routes and long foraging flights $[60,61]$ and are importantly thought to have shaped the evolution of migratory routes [1]. Also in this study, conditions aloft during actual migration trajectory was more favourable during outbound migration. However, it should be considered that simulated reverse migration probably underestimates thermal uplift and wind support, because it does not consider that birds actually chose favourable days for migratory flight (cf. Fig. 4), conditions aloft during reverse simulated migration might thus have been slightly better than depicted in Figs. 2 and 3. Moreover, it should be considered that aside from the here used calculation of wind-assistance, many other alternatives exist that could yield different outcomes and may (sometimes) be more appropriate depending on how Demoiselle cranes respond to flying in a moving medium route [62]. Another caveat that should be mentioned is that during our simulated reverse migration not only the aloft but also the stop-over conditions could potentially be underestimated, because the location of the stopover is fixed to the locations used by the Demoiselle cranes during the actual migration. However, inspection of the (NDVI) maps showed that if the Demoiselle cranes would have chosen to fly the routes at other times of the year, the locations where they stopped during actual migration would likely be the most suitable and productive at those other moments in the year.

Avian loop migrations are thought to be a very common migration phenomena, notably in the North-American and the Afro-Palearctic flyways [11, 19]. However, the underlying causes for loop migrations have rarely been addressed, with the exception of studies by Klaassen et al. [9] for Marsh harrier migration in the AfroPalearctic flyway and Sorte et al. [8] for terrestrial birds in western North America. Marsh harriers migrating between southern Sweden and western Africa, appeared to migrate in a relatively narrow, clockwise loop between southern Europe and western Africa [9]. The authors of that study tentatively concluded that general wind condition rather than foraging condition explained this loop migration. During inbound migration, many songbirds in western North America tend to use a more westerly and lower elevation route than during outbound migration, for which loop Sorte et al. [8] found differences in ecological productivity at the respective times of year to be responsible. Aside from these two studies that dealt with rather small loops, there have been other loop migrations for which mechanisms have been suggested, yet, not researched. For probably the biggest avian loop migration that has been documented to date, i.e. for Bar-tailed godwits (Limosa lapponica) in the Pacific, Gill Jr et al. [63] hypothesized that low food availability and high energetic demands upon arrival at the breeding grounds required a penultimate top-up stop in relatively close proximity 

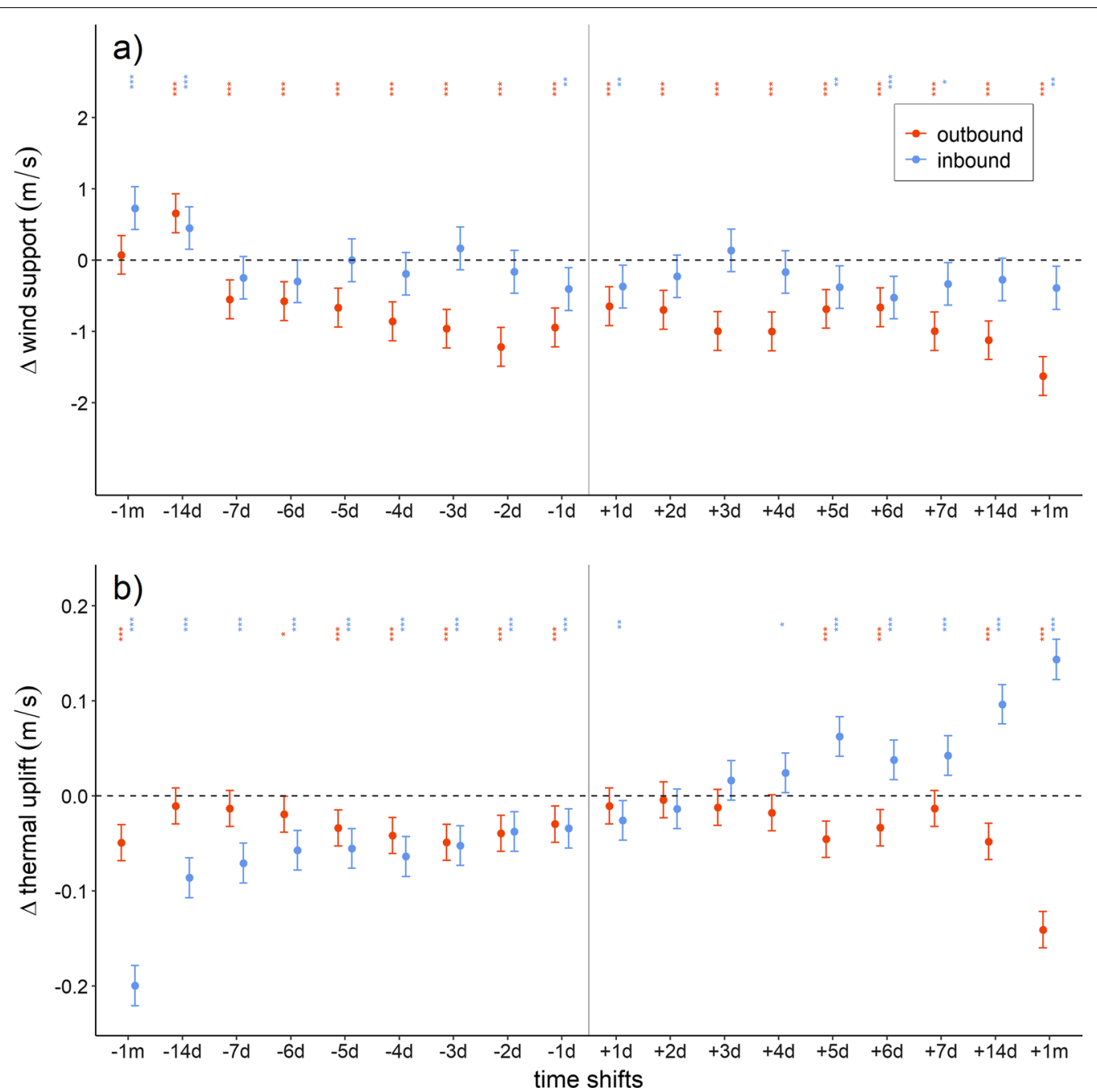

Fig. 4 Difference in wind support (a) and thermal uplift (b) between simulated, time-shifted migration and actual migration of Demoiselle cranes. Outbound and inbound migrations are depicted using red and blue symbols, respectively. X-axes reflect the simulated time-shifts of migration ranging from \pm 1 day to \pm 1 month. All variables are represented as difference between time-shifted and actual conditions $\pm 95 \%$ family-wise confidence level. Positive values indicate better and negative values indicate poorer conditions aloft than on actual days of migration. The significance level of multiple-comparison Dunnett's tests are indicated above each time-shift as ${ }^{*}(p<0.05),{ }^{* *}(p<0.01)$, and ${ }^{* *}(p<0.001)$. Horizontal dashed-line indicates the no-difference (i.e. same as actual) condition. Statistics and sample sizes are presented in Additional file 1

to those breeding grounds, driving this loop. Thus, our study in conjunction with existing studies and hypotheses $[5,8,9,11,19,63]$ on the underlying causes of loop migration show that the underlying factors determining loop migrations can vary across different geographical regions and taxonomic groups. Yet, in all cases the better understanding of loop migrations elucidates the constraints acting upon migrants and how these may vary between outbound and inbound migration, with critical implications for the conservation of migrants and the habitats on which they rely.

\section{Conclusions}

Although wind support and thermal uplifts are often crucial for successful migration, it was also on ground conditions in addition to these atmospheric factors that helped explain the remarkable loop migration in which Demoiselle cranes in East Asia engage. Our analyses notably suggested that better foraging conditions (i.e. higher NDVI) along the inbound route was explaining their preference to fly around the Himalayas rather than across. We therefore conclude that seasonal variations in on-ground and aloft environmental conditions importantly drive their choice of migration route. We consider that the here employed approach 
not only assist in understanding the trajectories of loop migrations but potentially also detour migrations. This approach and additional knowledge on the drivers for choice of migration trajectories facilitates predicting migration decisions and drafting mitigation strategies for global change effects on animal migrations.

\section{Supplementary Information}

The online version contains supplementary material available at https://doi. org/10.1186/s40462-022-00302-z.

Additional file 1. Figure S1. Illustration outlining reverse migration simulation. Table S1. Summary of environmental conditions during outbound and inbound migration of Demoiselle crane. Table S2. Differences in wind support of time-shifted outbound migration from actual migration. Table S3. Differences in wind support of time-shifted inbound migration from actual migration. Table S4. Differences in thermal uplift of time-shifted outbound migration from actual migration. Table S5. Differences in thermal uplift of time-shifted inbound migration from actual migration. Figure S2. Hourly distribution of wind support (a) and thermal uplift (c) flight height (b) and number of in-flight fix (d) during outbound and inbound migration.

\section{Acknowledgements}

We would like to express our gratitude to the field assistants Jugdernamjil Nergui, Baatarsuren Tsolmonbaatar, and Tuvshinjargal Erdenechimeg for their hard work to catch cranes in the field and to Kamran Safi, Anne Scharf, Wolfgang Fiedler, Graeme Hays and Hui Yu for their intellectual support during the various stages of this project. We also thank Judy Shamoun-Baranes and two anonymous reviewers who thoroughly reviewed the manuscript and provided many constructive comments.

\section{Authors' contributions}

BG and MK developed the idea and drafted the manuscript; BG carried out the statistical analyses with contributions from MK. BG, TS, NB, UM and MW carried out fieldwork and collected the movement data; NB and MW conceived and coordinated the study. BV and GH managed and prepared the transmitters; UM sought funding. All authors read and approved the final manuscript.

\section{Funding}

The Max Planck Society generously provided funding for the fieldwork. The Australian Endeavour Leadership Program funds BG's PhD candidature at Deakin University.

\section{Availability of data and materials}

The tracking data analysed during the current study is available on Movebank, under study names: LifeTrack Mongolia Demoiselle cranes and Demoiselle Crane High Resolution Mongolia. The annotated datasets analysed in this study is available on Dryad (https://doi.org/10.5061/dryad.cnp5hqc1r).

\section{Declarations}

\section{Ethics approval}

All procedures performed on tagged individuals complied with standard protocols approved by the Ministry of Environment and Tourism in Mongolia (licence: 04/2550).

\section{Consent for publication}

Not applicable.

\section{Competing interests}

The authors declare that they have no competing interests.

\section{Author details}

${ }^{1}$ Centre for Integrative Ecology, School of Life and Environmental Science, Deakin University, Victoria, Australia. ${ }^{2}$ Wildlife Science and Conservation Center of Mongolia, Ulaanbaatar, Mongolia. ${ }^{3}$ Department of Migration, Max Planck Institute of Animal Behavior, Radolfzell, Germany.

Received: 12 September 2021 Accepted: 12 January 2022 Published online: 31 January 2022

\section{References}

1. Newton I. The migration ecology of birds. Amsterdam: Elsevier; 2010.

2. Lindström A, Gill Jr RE, Jamieson SE, McCaffery B, Wennerberg L, Wikelski $M$, et al. A puzzling migratory detour: Are fueling conditions in Alaska driving the movement of juvenile sharp-tailed sandpipers? University of California Press, Journals Division; 2011.

3. Thompson D, Byrkjedal I. Tundra plovers: the Eurasian, Pacific and American golden plovers and grey plover: A\&C Black; 2010.

4. Tøttrup AP, Klaassen RHG, Strandberg R, Thorup K, Kristensen MW, Jørgensen PS, et al. The annual cycle of a trans-equatorial Eurasian-African passerine migrant: different spatio-temporal strategies for autumn and spring migration. Proc R Soc B: Biol Sci. 2012;279(1730):1008-16.

5. Alerstam T. Detours in bird migration. J Theor Biol. 2001;209(3):319-31.

6. Alerstam T. Bird migration: Cambridge University Press; 1993.

7. Briedis M, Kurlavičius P, Mackevičienè R, Vaišvilienè R, Hahn S. Loop migration, induced by seasonally different flyway use, in Northern European Barn Swallows. J Ornithol. 2018;159(4):885-91.

8. Sorte FAL, Fink D, Hochachka WM, DeLong JP, Kelling S. Spring phenology of ecological productivity contributes to the use of looped migration strategies by birds. Proc R Soc B: Biol Sci. 2014;281 (1793):20140984.

9. Klaassen RHG, Strandberg R, Hake M, Olofsson P, Tøttrup AP, Alerstam T. Loop migration in adult marsh harriers Circus aeruginosus, as revealed by satellite telemetry. J Avian Biol. 2010;41(2):200-7.

10. Mellone U, López-López P, Limiñana R, Piasevoli G, Urios V. The transequatorial loop migration system of Eleonora's falcon: differences in migration patterns between age classes, regions and seasons. J Avian Biol. 2013;44(5):417-26.

11. Schmaljohann H, Buchmann M, Fox JW, Bairlein F. Tracking migration routes and the annual cycle of a trans-Sahara songbird migrant. Behav Ecol Sociobiol. 2012;66(6):915-22.

12. Nourani E, Yamaguchi NM, Manda A, Higuchi H. Wind conditions facilitate the seasonal water-crossing behaviour of Oriental Honey-buzzards Pernis ptilorhynchus over the East China Sea. Ibis. 2016;158(3):506-18.

13. Shaffer SA, Tremblay Y, Weimerskirch H, Scott D, Thompson DR, Sagar PM, et al. Migratory shearwaters integrate oceanic resources across the Pacific Ocean in an endless summer. Proc Natl Acad Sci. 2006;103(34):12799-802.

14. Patchett R, Cresswell W. Regional wind patterns likely shape a seasonal migration detour. J Avian Biol. 2020;51(11).

15. Sorte FAL, Fink D, Hochachka WM, Farnsworth A, Rodewald AD, Rosenberg KV, et al. The role of atmospheric conditions in the seasonal dynamics of North American migration flyways. J Biogeogr. 2014;41(9):1685-96.

16. DeLuca WV, Woodworth BK, Rimmer CC, Marra PP, Taylor PD, MCFarland $\mathrm{KP}$, et al. Transoceanic migration by a $12 \mathrm{~g}$ songbird. Biol Let. 2015;11(4):20141045.

17. Willemoes M, Strandberg R, Klaassen RHG, Tøttrup AP, Vardanis Y, Howey PW, et al. Narrow-front loop migration in a population of the common cuckoo Cuculus canorus, as Revealed by Satellite Telemetry. PLOS ONE. 2014;9(1):e83515.

18. Klvaňa P, Cepák J, Munclinger P, Michálková R, Tomášek O, Albrecht T. Around the Mediterranean: an extreme example of loop migration in a long-distance migratory passerine. Journal of Avian Biology. 2018;49(2).

19. Evens R, Conway GJ, Henderson IG, Cresswell B, Jiguet F, Moussy C, et al. Migratory pathways, stopover zones and wintering destinations of Western European Nightjars Caprimulgus europaeus. Ibis. 2017:159(3):680-6.

20. Guilford T, Meade J, Willis J, Phillips RA, Boyle D, Roberts S, et al. Migration and stopover in a small pelagic seabird, the Manx 
shearwater Puffinus puffinus: insights from machine learning. Proc Biol Sci. 2009;276(1660):1215-23.

21. González-Solís J, Felicísimo A, Fox JW, Afanasyev V, Kolbeinsson Y, Muñoz J. Influence of sea surface winds on shearwater migration detours. Mar Ecol Prog Ser. 2009;391:221-30.

22. Higuchi H, Minton J. Migratory Routes across the Himalayas Used by Demoiselle Cranes. In: Prins HHT, Namgail T, editors. Bird Migration Across the Himalayas: Wetland Functioning amidst Mountains and Glaciers. Cambridge: Cambridge University Press; 2017. p. 45-57.

23. Yumin G, Fenqi He. Preliminary result of Satellite Tracking on Ordos Demoiselle Cranes. Chin J Wildlife. 2017;38(1):141-3.

24. Liechti F, McGuire LP. Facing the wind: The aeroecology of vertebrate migrants. Aeroecology 2018. p. 179-98.

25. Shamoun-Baranes J, Liechti F, Vansteelant WMG. Atmospheric conditions create freeways, detours and tailbacks for migrating birds. J Comp Physiol A. 2017;203(6):509-29.

26. Alerstam T. Common crane (Grus grus) migration over sea and land. Ibis. 1975;117(4):489-95.

27. Pennycuick CJ, Alerstam T, Larsson B. Soaring Migration of the Common Crane Grus grus Observed by Radar and from an Aircraft. Ornis Scandinavica (Scand J Ornithol). 1979;10(2):241-51.

28. Sarwar M, Hussain I, Khan A, Anwar M. Diet composition of the Demoiselle Crane (Anthropoides virgo) migrating through Lakki Marwat. Pak Avian Biol Res. 2013;6(4):269-74.

29. Meine C, Archibald G. The cranes: status survey and conservation action plan: IUCN; 1996.

30. Propastin P, Kappas M, Muratova N. Inter-annual changes in vegetation activities and their relationship to temperature and precipitation in Central Asia from 1982 to 2003. J Environ Inform. 2008;12(2):75.

31. Yu F, Price KP, Ellis J, Shi P. Response of seasonal vegetation development to climatic variations in eastern central Asia. Remote Sens Environ. 2003;87(1):42-54

32. Fernández-Tizón M, Emmenegger T, Perner J, Hahn S. Arthropod biomass increase in spring correlates with NDVI in grassland habitat. Sci Nature. 2020;107(5):42.

33. Hedenström A, Åkesson S. Ecology of tern flight in relation to wind, topography and aerodynamic theory. Philos Trans R Soc B: Biol Sci. 2016:371(1704):1-9.

34. Liechti F. Birds: Blowin' by the wind? J Ornithol. 2006;147(2):202-11.

35. Beekman JH, Nolet BA, Klaassen M. Skipping swans: fuelling rates and wind conditions determine differential use of migratory stopover sites of Bewick's Swans Cygnus bewickii. Ardea. 2002:90(3):437-60.

36. Klaassen M, Beekman JH, Kontiokorpi J, Mulder RJW, Nolet BA. Migrating swans profit from favourable changes in wind conditions at low altitude. J Ornithol. 2004;145(2):142-51.

37. Ellis DH, Howey PW, Krapu GL. Recommendations for the attachment of satellite transmitters to cranes. 2001.

38. Hersbach H, Bell B, Berrisford P, Hirahara S, Horányi A, MuñozSabater J, et al. The ERA5 global reanalysis. Q J R Meteorol Soc 2020;146(730):1999-2049

39. Dodge S, Bohrer G, Weinzierl R, Davidson SC, Kays R, Douglas D, et al. The environmental-data automated track annotation (Env-DATA) system: linking animal tracks with environmental data. Mov Ecol. 2013;1 (1):3.

40. Kranstauber B, Smolla M, Scharf AK. move: Visualizing and Analyzing Animal Track Data. R package version 3.2.2. ed 2019.

41. Safi K, Kranstauber B, Weinzierl R, Griffin L, Rees EC, Cabot D, et al. Flying with the wind: Scale dependency of speed and direction measurements in modelling wind support in avian flight. Movement Ecol. 2013;1 (1):4.

42. Bohrer G, Brandes D, Mandel JT, Bildstein KL, Miller TA, Lanzone M, et al. Estimating updraft velocity components over large spatial scales: contrasting migration strategies of golden eagles and turkey vultures. Ecol Lett. 2012;15(2):96-103.

43. Ventura F, Granadeiro JP, Padget O, Catry P. Gadfly petrels use knowledge of the windscape, not memorized foraging patches, to optimize foraging trips on ocean-wide scales. Proc R Soc B: Biol Sci. 1918:2020(287):20191775.

44. R Core Team. R: A language and environment for statistical computing. $R$ Foundation for Statistical Computing. Vienna, Austria. 2020.

45. Dunnett CW. A multiple comparison procedure for comparing several treatments with a control. J Am Stat Assoc. 1955;50(272):1096-121.
46. van Wijk RE, Kölzsch A, Kruckenberg H, Ebbinge BS, Müskens GJDM, Nolet BA. Individually tracked geese follow peaks of temperature acceleration during spring migration. Oikos. 2012;121(5):655-64.

47. Tøttrup AP, Thorup K, Rainio K, Yosef R, Lehikoinen E, Rahbek C. Avian migrants adjust migration in response to environmental conditions en route. Biol Let. 2008;4(6):685-8.

48. Hadjikyriakou TG, Nwankwo EC, Virani MZ, Kirschel ANG. Habitat availability influences migration speed, refueling patterns and seasonal flyways of a fly-and-forage migrant. Mov Ecol. 2020;8(1):10.

49. Thorup K, Tøttrup AP, Willemoes M, Klaassen RHG, Strandberg R, Vega ML, et al. Resource tracking within and across continents in long-distance bird migrants. Sci Adv. 2017;3(1):e1601360.

50. Mi C, Li X, Huettmann F, Goroshko O, Guo Y. Time and energy minimization strategy codetermine the loop migration of demoiselle cranes around the Himalayas. Integr Zool. 2022. https://doi.org/10.1111/17494877.12632.

51. Prins HHT, Namgail T. Bird Migration Across the Himalayas: Wetland Functioning amidst Mountains and Glaciers. Prins HHT, Namgail T, editors. Cambridge: Cambridge University Press; 2017.

52. Ydenberg RC. The Himalayas as an Ecological Barrier for Avian Migrants: High and Dry, but also Dangerous? In: Prins HHT, Namgail T, editors. Bird Migration Across the Himalayas: Wetland Functioning amidst Mountains and Glaciers. Cambridge: Cambridge University Press; 2017. p. 283-98.

53. Mirande CM, Harris JT. Crane conservation strategy. International Crane Foundation, Baraboo. 2019

54. Végvári Z, Barta Z. Roost site selection of the common crane in Its Largest European Stop-Over Site. Ardea. 2015;103(2):175-81.

55. Hawkes LA, Balachandran S, Batbayar N, Butler PJ, Chua B, Douglas DC, et al. The paradox of extreme high-altitude migration in bar-headed geese (Anser indicus). Proc R Soc B: Biol Sci. 2013;280(1750):20122114.

56. Dixon A, Rahman L, Sokolov A, Sokolov V. Peregrine Falcons Crossing the 'Roof of the World.' In: Prins HHT, Namgail T, editors. Bird Migration Across the Himalayas: Wetland Functioning amidst Mountains and Glaciers. Cambridge: Cambridge University Press; 2017. p. 128-42.

57. Namgail T, Takekawa JY, Balachandran S, Palm EC, Mundkur T, Vélez VM, et al. Himalayan Thoroughfare: Migratory Routes of Ducks over the Rooftop of the World. In: Prins HHT, Namgail T, editors., et al., Bird Migration Across the Himalayas: Wetland Functioning amidst Mountains and Glaciers. Cambridge: Cambridge University Press; 2017. p. 30-44.

58. Alerstam T, Hedenström A, Åkesson S. Long-distance migration: evolution and determinants. Oikos. 2003;103(2):247-60.

59. Johnsgard PA. Cranes of the World: Indiana University Press; 1983.

60. Weimerskirch H, Guionnet T, Martin J, Shaffer SA, Costa DP. Fast and fuel efficient? Optimal use of wind by flying albatrosses. Proc R Soc B: Biol Sci. 2000;267(1455):1869-74.

61. Schmaljohann H, Naef-Daenzer B. Body condition and wind support initiate the shift of migratory direction and timing of nocturnal departure in a songbird. J Anim Ecol. 2011;80(6):1115-22.

62. Kemp MU, Shamoun-Baranes J, van Loon EE, McLaren JD, Dokter AM, Bouten W. Quantifying flow-assistance and implications for movement research. J Theor Biol. 2012;308:56-67.

63. Gill RE Jr, Tibbitts TL, Douglas DC, Handel CM, Mulcahy DM, Gottschalck $J C$, et al. Extreme endurance flights by landbirds crossing the Pacific Ocean: ecological corridor rather than barrier? Proc R Soc B: Biol Sci. 2009;276(1656):447-57.

\section{Publisher's Note}

Springer Nature remains neutral with regard to jurisdictional claims in published maps and institutional affiliations. 